\title{
On the Birthday of R. M.-F. Salikhdzhanova
}

DOI: $10.1134 / \mathrm{S} 1061934808040187$

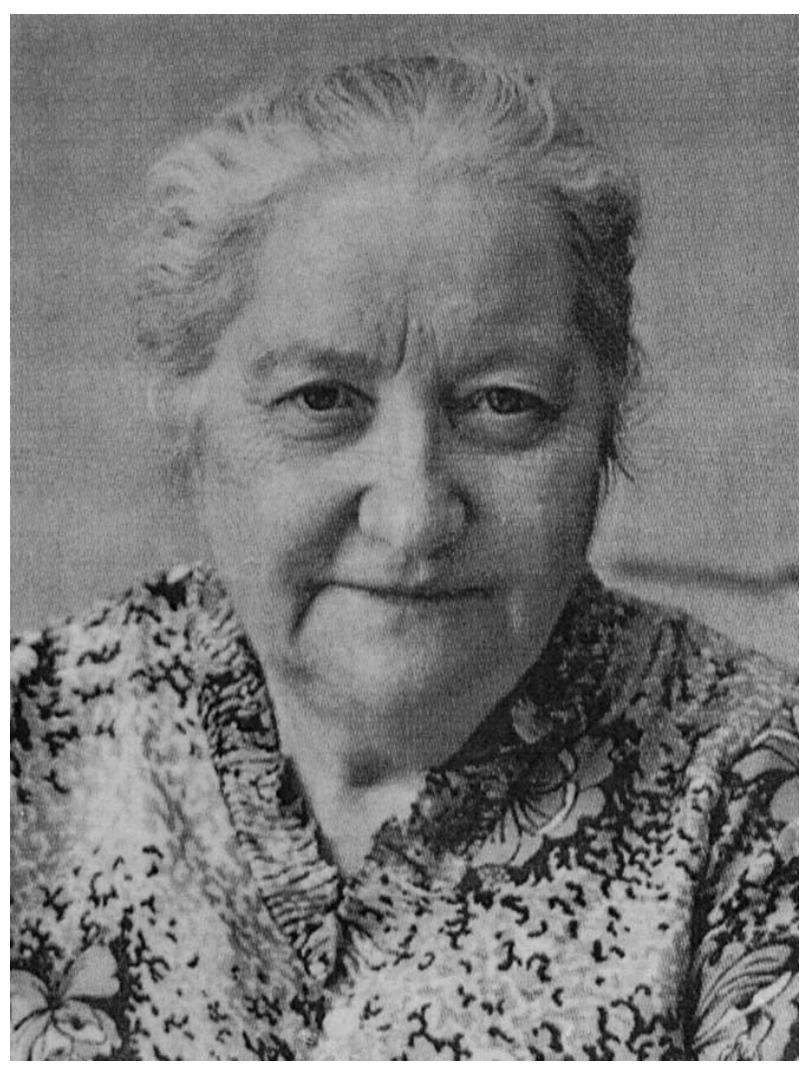

January 5, 2008 was the 75th birthday of Professor Rashida Muhamet-Fatikhovna Salikhdzhanova, doctor of technical sciences. She graduated from the Maurice Thorez Pedagogical Institute of Foreign Languages in 1957, while simultaneously studying at the radio engineering department of the Moscow Power Institute. Later, she worked as a teacher of German at the Moscow Power Institute and at a young workers' school, and, then, was a translator, reviewer, and editor in abstract journals. After graduating from the Moscow Power Institute in 1960, Salikhdzhanova was placed at the Central Laboratory of Automatics (later, the AllUnion Research Institute for Automation in Iron and Steel Industry, VNIIAchermet) in the group headed by the leading expert in domestic routine polarographic instrument-making S.B. Tsfasman; under his supervision, she actively worked until 1965, and then headed the group. In 1966, after finishing graduate courses at the Moscow Institute of Chemical Mechanical Engineering via correspondence, Salikhdzhanova defended her candidate's dissertation and became a candidate of technical sciences. At VNIIAchermet, she moved from an engineer to a senior researcher. She directly participated in the design of polarographic instruments of new types, which were widely used in laboratories both in Russia and abroad. In 1975, Rashida MuhametFatikhovna came to the Moscow Institute of Radio, Electronics, and Automatics. In 1982, she defended her doctoral dissertation "Relaxation voltammetry with the application of a trapezoid shape", which opened up a new direction in electrochemical analysis. For more than 20 years, Salikhdzhanova headed the division of the design and manufacture of radio-electronic devices. Now, she is a professor at the division, working in the automation and computerization of voltammetric instruments. The results of Professor Salikhdzhanova's research and pedagogical activity have been covered in numerous publications, more than 300 scientific works, including 5 monographs and 7 student's textbooks. She participated in the development of voltammetric setups of 6 types and was given 15 inventor's certificates. In 2002, Salikhdzhanova was awarded the honorary title of honored worker of higher education of the Russian Federation.

Professor Salikhdzhanova has been a member of the Scientific Council on Analytical Chemistry of the Russian Academy of Sciences for many years and headed its section on analytical instruments; she headed the section on electroanalytical instruments in one of the councils of the Ministry of Instrument Making of the USSR, was a member of the section on the control of the chemical composition of materials, and served as the scientific leader of a series of lectures on modern instruments and equipment for chemical and spectrochemical laboratories at the Moscow House of Scientific and Technical Propagation (later, the House of Knowledge); she has also sat on some dissertation councils, including those at the Vernadsky Institute of Geochemistry and Analytical Chemistry and Moscow State University, and was a member of the bureau of the Moscow Branch of the Mendeleyev Russian Chemical Society. For many years, she has worked on the editorial boards of the journal "Zavodskaya Laboratoriya. Diagnostika Materialov." Analytical chemists, friends and colleagues, and the numerous students of Professor Salikhdzhanova cordially congratulate Rashida Muhamet-Fatikhovna on her birthday and wish her good health and further creative successes. 